Methods 69 adolescents, (10.4-18.0 years), were assessed at their initial clinic appointment using a three-part questionnaire. Their parents received one part of this questionnaire separately. The questionnaire was comprised of three survey instruments which had been previously validated for use in adolescents. Additional data about the adolescents was collected from their clinic assessment form.

Results $69.6 \%$ of the adolescents were female, $13.0 \%$ were obese or very obese and mean illness duration was 25.3 months. $36.2 \%$ of the adolescents came from a household within the $10 \%$ most affluent in the country. Moderate, severe or extreme anxiety or depression symptoms were reported by $39.1 \%$, severe levels of worry by $43.5 \%$ and high or very high symptom impact by $69.1 \%$. Long illness duration was significantly associated with low $\operatorname{mood}(p=0.006)$ but no other associations were significant. There was minimal agreement between the adolescents' and parents' answers (mean kappa score $=0.373$ ) with the parents reporting $\mathrm{CFS} / \mathrm{ME}$ to cause greater difficulties.

Conclusions Adolescents from high-income backgrounds are over-represented amongst adolescents attending this specialist clinic. This may represent higher prevalence or greater access to specialist services in high-income families. More than a third of adolescents attending this clinic reported significantly reduced quality of life and/or low or anxious mood symptoms; more than two thirds reported that the condition has a major impact on their daily life. Parents report CFS/ME to cause greater difficulties than their children do.

\section{G14(P) UNDERSTANDING YOUNG PEOPLE WITH DIABETES: USING EXPERIENCE BASED CO-DESIGN TO PROVIDE A PATIENT-CENTRED DIABETES TRANSITION SERVICE}

A Soni, E Freeman. General Paediatrics, Royal Free London NHS Foundation Trust, London, UK

\subsection{6/archdischild-2018-rcpch.14}

Aim To use experience based co-design to improve the Diabetes Transition Service.

Design Young people with diabetes (type 1 and 2) managed by a district general Paediatric Diabetes Team, were invited to attend a focus group.

The focus group, held in a local café, afterschool, was facilitated by 2 members of the Paediatric Diabetes team and the Diabetes Psychologist.

A graphic designer attended to support the young people to visually explore and communicate their experiences and ideas. Results 5 young people attended the group, ages 15-17 years. Each attendee was invited to tell their diabetes story, followed by facilitated individual and group discussions about the transition service and health and social wellbeing of young people in relation to diabetes.

Recurrent themes that emerged included: promotion of independence, consistency of care, access to information and support via email and the internet, and the desire for peersupport opportunities.

Changes in administration at the time of transition was highlighted to promote self-advocacy. The attendees strongly preferred physicians to be direct in their communication styles and to be seen individually by each member of the diabetes multidisciplinary team. They emphasised the need for after- school appointments and agreed that the hospital was a convenient location.

The attendees were all keen on receiving information about diabetes and driving, alcohol, drugs, exam stress, contraception and pregnancy, some indicating a preference for written information (leaflets/website links) and others face to face discussions.

All attendees identified a strong desire for the team to facilitate email contact and social events with others transitioning and those who have transitioned.

$100 \%$ of the young people said that they would attend another focus group.

Conclusion This focus group wants a diabetes transition service that promotes self-advocacy and independence, allows them to see the same consultant who communicates openly and directly, have access to information about how diabetes affects issues facing young people, and a service that provides them with ongoing peer-support.

Experience based co-design can ensure that diabetes transition services provide young people with a patient-centred service, that promotes ongoing health and social wellbeing well in to adulthood.

\section{G15(P) ABSTRACT WITHDRAWN}

\section{G16(P) YOUTH PERSPECTIVE ON THE 'SEXUALITY EDUCATION: LESSONS LEARNED AND FUTURE DEVELOPMENTS IN THE WHO EUROPEAN REGION' CONFERENCE 2017}

\footnotetext{
1,2,3M Gray. ${ }^{1}$ The Medical School, The University of Sheffield, Sheffield, UK; ${ }^{2}$ YSAFE, (IPPF European Network), Brussels, Belgium; ${ }^{3}$ Family Planning Association Youth Council, Family Planning Association, London, UK
}

\subsection{6/archdischild-2018-rcpch.15}

Background and aims Comprehensive sex education is a successful intervention approach to improving the mental and physical health of children, and is a crucial factor in developing the ability of young people to exercise informed autonomy over their sexual and reproductive rights and wellbeing. It is also recognised as a safeguarding factor against child sexual exploitation. As a member of the Sheffield branch of the sex education charity Sexpression, and the FPA Youth Council, I was invited to join a youth delegation at the Sexuality Education conference to share a youth perspective on past successes and failures in the WHO European Region.

Methods Data was collected from research by WHO, and the United Nations Populations Fund amongst others, and qualitative information gathered through focus groups and fishbowl discussions with international delegates

Results Country representatives raised challenges such as misconceptions about sexuality education and a perceived drop in moral standards, questioning of the role of the school vs. parental education, political and religious resistance, and the feasibility of sustainable programmes. Presented were positive examples of primary school age targeted sex education programmes, and the use of technology to provide information to younger audiences. The youth delegation were given a chance to feed back their perspective on national and local education and health initiatives. They noted the use of 'jargon' and inaccessible language in education and services. The lack of representation from central Asia and other gender 